segundo e inesperado dato: que $E l$ Politico, a pesar de las afirmaciones de Latasa (seguido por la tropa de gracianistas), no fue publicado por Lastanosa, el cual sólo tomó la iniciativa en la segunda impresión.

Ya hemos descubierto el escueto título de uno de los tratados perdidos, de uno de los "doze Gracianes" puestos a contribución para componer el Oráculo manual. Quedan interiormente formuladas y sin posible respuesta las inevitables cuestiones: ¿Por qué no publicó $-\mathrm{y}$ acaso ni siquiera acabó- el libro planeado? ¿Influyeron en su renuncia las sublevaciones de Cataluña y Portugal, el cuarteamiento del Imperio español, el descrédito de los ministros reales? ¿Qué fragmentos han sido utilizados para el mosaico del Oráculo manual? La vida y la obra de Gracián abundan en laberintos sin hilo documental que nos guíe a solución segura.

Eugenio Asensio

Lisboa.

\title{
MÁS SOBRE MONTALVO Y MENÉNDEZ PELAYO
}

Al aparecer mi artículo sobre "Montalvo y Menéndez Pelayo" (NRFH, 11, 366-985), los doctores Julio Torri y Emilio Uranga, catedráticos de la Facultad de Filosofía y Letras de la Universidad de México, me dieron noticia verbal de las referencias a Montalvo que figuran en el Epistolario de Menéndez Pelayo y Rodriguez Marin (Madrid, 1935), no utilizadas por mí. Se trata del juicio de Menéndez Pelayo sobre los Capitulos que se le olvidaron a Cervantes, obra póstuma de Montalvo excluida del examen cronológico de mi trabajo, que en realidad no altera mis conclusiones, antes las refuerza.

En carta fechada en "Sevilla, 3 de noviembre de 1896 ", don Francisco Rodríguez Marín propuso la cuestión: "He leído el decantadísimo libro de Montalvo. Cuando esos capítulos se le olvidaron a Cervantes, paréceme que no durmió, sino que estuvo muy despierto. ¿No cree usted lo mismo?" (p. 73). Don Marcelino contestó desde "Santander, 8 de enero de 1897 ", lo siguiente: "Veo que el librote del americano Montalvo le hizo a usted la misma impresión que a mí. Confieso que no pude acabar su lectura, ¿Qué fárrago tan insulso! iQué falta de gracia y de amenidad! Pero ¿qué podía esperarse de un hombre que tiene la temeridad de completar a Cervantes, y aun de enmendarle la plana?" (p. 78 ).

Por lo pronto, es notoria la injusticia de atribuir a Montalvo semejante intención; Montalvo, quizá no con humildad, pero sí consciente de sus limitaciones, convino que su obra fuera sólo un "ensayo de imitación de un libro inimitable", como reza la portada ${ }^{1}$. El despectivo "librote" con que se inicia la andanada se explica como un arranque

1 Capitulos que se le olvidaron a Cervantes. Ensayo de imitación de un libro inimitable. Obra póstuma de Juan Montalvo. Imprenta de P. Jacquin, Besanzón 1895 . Menéndez Pelayo conservó un ejemplar de la segunda edición (Montaner y Simón, Barcelona, 1898 ), con dedicatoria de los editores; signatura $2595 / 4175$, en su Biblioteca, Santander. El propio Montalvo, al incluir entre los Siete tratados, en 1882, el Buscapié de los Capitulos, ya se curaba en salud de los posibles cargos que se le harían a la publicación de la obra: "Mas cuando estamos señalando los defectos del vecino y fiscalizando su manera de escribir, no sabemos si nosotros mismos vamos cayendo en otros peores; y así, por no volvernos culpables de fatuidad sobre la nota de ignorantes, hemos preferido la culpa del atrevimiento, bautizándola con el nom- 
explosivo, intimo, con el colega de la misma edad, que lo interroga en privado; la condición "póstuma" de la obra ayuda a liberar la sinceridad. Vivo Montalvo, la opinión de Menéndez Pelayo, aun "manifestada confidencialmente", habría sido menos dura; así debió de ser la que confió a Valera en $188_{3}(N R F H, 11$, p. 367 , nota 5). Es significativo que a Valera en 1897 , aunque ha muerto Montalvo, no le diga palabra sobre la reciente edición de los Capitulos, a lo largo del copioso epis. tolario de esas fechas: Valera le lleva treinta y un años, suele ser indulgente con los hispanoamericanos, ha elogiado ya públicamente a Montalvo, e incluso llegó a cartearse con él ${ }^{2}$.

Cinco años más tarde, vuelve Menéndez Pelayo sobre el mismo tema. Otra vez, en carta a Rodríguez Marín, de "Madrid, 29 de enero de 1902", a propósito de las imitaciones cervantinas, y sin previa solicitud del corresponsal, incurre en la repetición de los propios juicios, con casi las mismas palabras, costumbre suya que ya he señalado ( $N R F H$, 11 , p. 379 , notas 25 y 26). Aquí, además de lo "fastidioso" de los Capitulos (recuérdese el "fárrago tan insulso" de la carta de 1897), lo reiterado es la "temeridad" de Montalvo: ahora, "supuso temerariamente", resulta paralelo a "tiene la temeridad". Conviene copiar todo el párrafo, para ver el punto de comparación: "Hablando a usted de cosas menos tristes, le diré que he leído con mucho placer el ingenioso libro cervantino de nuestro amigo Abaúrre ${ }^{3}$. Es de amena lección y tiene rasgos muy felices, como el arrepentimiento y locura de Sansón Carrasco. El estilo es algo híbrido, y me desagradan ciertas frases modernas mezcladas con otras castizas y que prueban frecuente y aprovechado estudio del Quijote. De todos modos, es una de las tentativas de su género que más me satisfacen, y aventaja con mucho a aquellos fastidiosos capitulos que el americano Montalvo supuso temerariamente que se le habían olvidado a Cervantes" (p. 205). Tampoco en estos días Menéndez Pelayo se atrevió a confiar a Valera su juicio estereotipado. Valera escribía entonces la carta-prólogo a la Geometria moral, la otra obra póstuma de Montalvo ${ }^{4}$.

A estas rápidas notas puedo agregar ahora otras sobre la pretendida elección y el rechazo académicos de Montalvo y la opinión de los críticos respecto del asunto. No hay acuerdo unánime, pero el orden crono-

bre de Capitulos que se le olvidaron a Cervantes" (Siete tratados, París, [1923], t. 2, p. $\left.3^{62}\right)$. xima.

${ }_{2}^{2}$ Me propongo puntualizar las relaciones de Valera y Montalvo en una nota pró-

${ }^{3}$ José Abaúrre y Mesa, Historia de varios sucesos ocurridos en la aldea después de la muerte del ingenioso hidalgo don Quijote de la Mancha, Madrid, 1901 (2 vols.). E1 mismo Abaúrre había publicado poco antes Un capitulo del Quijote (Sevilla, 1898 ), alentado al parecer por la crítica encomiástica que tuvo el Buscapié de los Capitulos. "Fue éste [el Buscapié] declarado entonces, en modo unánime, al más estupendo y digno elogio de Cervantes,, cescrito en la prosa castellana más elegante, noble, pura y numerosa que se ha compuesto en el siglo xrxs, como dijo Navarro Ledesma y lo refrendó Núñez de Arce, y lo repitieron desde Valera hasta Gómez de Baquero" (Gonzalo Zaldumbide, Prólogo a El Espectador, París, 1927, p. xii).

4 Juan Montalvo, Geometria moral. Con una carta-prólogo de don Juan Valera. Est. Tip. "Sucesores de Rivadeneyra", Madrid, 1902. La carta-prólogo, fechada en "Madrid, 25 de agosto de 1902", está dirigida "Al señor don Leonidas Pallares Artera, París". El ejemplar de Menéndez Pelayo se conserva en su Biblioteca (Santander), signatura $2715 / 20764$. 
lógico deja ver el progreso de lo novelesco del incidente: Gonzalo Zaldumbide, ecuatoriano devoto de Montalvo y prologuista de El Espectador (1927), no se hace eco del supuesto agravio: "La acogida que halló [Montalvo] en la villa y corte y le dispensó la Academia, discreta fue, no la que el rango y alcurnia de tan castizo mantenedor del fuero del idioma merecía. La Pardo Bazán, Castelar, Campoamor, Núñez de Arce, lo recibieron y guiaron. La prensa lo saludó cual cumple a un huésped distinguido, sin más. Se habló sin duda de él en cenáculos y corros literarios. Pero la crítica propiamente dicha tardó en pronunciarse públicamente, y no lo hizo en suma sino después de su muerte, a la aparición de la primera obra póstuma, los Capitulos que se le olvidaron a Cervantes y a propósito de su prólogo"s. Otro devoto de Montalvo, Roberto Agramome, compilador y prologuista de las Páginas desconocidas (1936), concreta el cargo en la persona de don Aureliano Fernández Guerra y Orbe: "en este año [el de 1887] aparece $E l$ vejes. torio ridiculo, contra el secretario de la Academia Española, que se opone a su ingreso en ella, a pesar de haber sido patrocinado por Castelar, Núñez de Arce y otros" ${ }^{6}$. Finalmente, el señor Gustavo Vascónez Hurtado, en Pluma de acero o La vida novelesca de Juan Montalvo (1944), da vuelo a la suya: "Ramón de Campoamor, bien impresionado por sus méritos de literato [de Montalvo], ayudará y patrocinará su entrada a la Real Academia Española... Emilio Castelar, Ramón de Campoamor y Gaspar Núñez de Arce hacen lo posible para que el literato ecuatoriano sea nombrado miembro correspondiente de la Real Academia Española; pero sus ideas religiosas, su lucha contra el fanatismo y las falsas doctrinas, acaso el hecho de ser el autor de algunas páginas de las Catilinarias y La dictadura perpetua, hacen que la proposición de los nombrados académicos sea rechazada en un ambiente en donde predominan los principios conservadores... El hecho de no haber sido nombrado miembro de la Real Academia será una espina para el orgulloso literato; la lleva clavada en el pecho y aquélla le producirá sobresaltos de amargura y desencanto" ". No se puede ser más patético. Pero mientras la Comisión Administrativa de la Academia de Madrid no se digne revocar el acuerdo del acta de 7 de noviembre de 1946, tendremos que esperar el año 2033 de nuestra era atómica para averiguar este pequeño incidente, o dar todo crédito a las palabras de Montalvo: "No es verdad, como han propagado mis mal querientes, que yo haya sufrido un rechazo, pues nunca he sido propuesto".

El Colegio de México.

ERnesto Mejía Sánchez

5 G. Zardumbide, Prólogo cit., pp. xi-xii.

${ }^{6}$ Roberto Agramonte, Prólogo a las Páginas desconocidas de Juan Montalvo, La Habana, 1936, p. xiii. El vejestorio ridiculo está dirigido en efecto contra Fernández Guerra, pero éste no era secretario, sino bibliotecario de la Academia; el secretario era Tamayo y Baus, como nos dice el propio Montalvo: "Don Aureliano, a fuer de bibliotecario de la dicha Academia, tiene posada en ella, lo mismo que don Manuel Tamayo y Baus a titulo de secretario" (Mercurial eclesiástica y Un vejestorio ridiculo, Madrid, s. f., p. 185).

7 Gustavo Vascónez Hurtado, Pluma de acero, o La vida novelesca de Juan Montalvo, México, 1944, pp. 203-205.

\& NRFH, 11 (1957), pp. 369-37o, notas 6 y 8. 